\title{
TWO CASES OF TEMPORAL ARTERITIS: ONE WITH ANGINA OF EFFORT
}

BY

\author{
LESLIE COLE \\ From Addenbrooke's Hospital, Cambridge \\ Received December 14, 1947
}

Temporal arteritis was first described as a separate syndrome by Horton, Magath, and Brown in 1932. The clinical features of headache associated with inflamed and tender temporal arteries, the histological appearance of excised portions of these arteries, and the apparently self-limited course of the disease led them to suggest that this was a new clinical entity. Since then about forty cases have been recorded and in an excellent résumé of these, which included seven of their own, Cooke, Cloake, Govan, and Colbeck (1946) have produced clinical and pathological evidence to support their view that temporal arteritis is a generalized vascular disease that is distinct clinically and pathologically from thrombo-angiitis obliterans and periarteritis nodosa. They point out that the characteristic clinical features are anorexia, loss of weight, joint and muscle pains, pyrexia, painful arterial thrombosis, and severe headaches occurring in elderly patients; and that at least half so far reported have had visual disturbances leading in many instances to complete loss of sight. In two cases a characteristic histological picture was noted in all the main arteries of the body including the aorta and coronaries.

Since 1931 I have had three patients with the disease, under observation. Details of the first were published previously in a paper by Jennings (1938). Of the other two described here, one suffered from severe angina of effort in addition to characteristic signs and symptoms, and died in a typical attack of coronary thrombosis. In other respects all three were remarkably similar.

\section{CASE Notes}

Case 1.-A man, aged 68, who until the age of 65 had worked as a farmer, was sent to me on December 4, 1945, for severe temporal headache.
In 1942 he began to suffer from pain in the middle of the chest on exertion which passed off when he rested. This gradually grew more severe so that he was forced to give up work, and by October 1945 he could not walk more than 200 yards without resting. The pain was gripping in character and when severe tended to radiate all over the chest and up into the neck. It was worse in cold weather but did not come on apart from effort. At the end of October he developed a pain in the left temple. This was stabbing in character and in a few days became extremely severe. At the same time he noticed that the "veins" in his temple got quite thick and his head felt "wooden." The pain came on in bouts which would sometimes last all day or night, and was at times "almost unbearable." At the end of a week the same trouble came on in the right temple with similar severe pain and the "veins" there became swollen. The condition in both temples continued with varying severity until I saw him on December 4, when the frequency and duration of the attacks had somewhat lessened.

In the past he had had no serious illnesses but had suffered from "rheumatism" in the shoulders, back, and thighs, for some years which had become worse. He had lived a strenuous life as a farmer in the Fens and smoked and drank moderately. His father died suddenly at the age of 56 and his mother died in her sleep at 70 . He thought that his grandparents had lived to a good age and there was nothing else significant in the family history.

On examination, the temporal arteries on both sides appeared swollen, tender and tortuous, and there appeared to be a good deal of periarterial swelling. There was some redness of the skin in places over the right temporal artery. The occipital arteries were not affected. Pulsation in the arteries was very slight or absent. The radial and brachial 
arteries showed very slight thickening and tortuosity. The optic discs did not show any abnormality. A localized systolic murmur was audible at the apex, in all positions, but the heart sounds were otherwise normal. Cardioscopy did not show any enlargement. The cardiogram was normal and the Wassermann reaction on the blood negative. The urine was normal. The blood count did not show any change except a leucocytosis of 10,500 with 76 per cent polymorphs. The movements of the back and joints were fairly free for a man of his age and type, and the other systems appeared normal.

Progress.-During the next fortnight the attacks of pain in the head gradually became less severe and frequent, the swelling of the temporal arteries almost subsided and the tenderness and redness disappeared but pulsation was still difficult to detect. By May, his headache had completely gone but the pain in his chest was more severe and brought on even by shaving. His general condition had deteriorated and he had lost 16 pounds in weight in four months. Some tortuosity and periarterial thickening of the temporal arteries remained but the tenderness had gone. The cardiogram was unchanged. During the summer of 1946 his general condition improved considerably, he gained weight and the pain in his chest grew less severe and he was able to walk about a little. He died in September a few hours after what appeared to be a typical attack of coronary thrombosis.

Case 2.-A man, aged 64, was admitted to Addenbrooke's Hospital on January 18, 1938, for pain in the head and fever. In October 1937 he developed pains in the back of the neck, shoulders, left elbow and legs, which he attributed to working in a damp place. These pains persisted intermittently and especially affected his left hand so that he found he had difficulty in holding his tools. A few weeks after the onset, pains in his forehead came on, gnawing and aching in character, lasting ior $4^{-5}$ hours at a time, and made worse by movement. He also found that he could not see clearly to read and that a bright light would bring on a throbbing pain behind the eyes. These symptoms persisted until he was admitted.

In the past he had pleurisy and pneumonia about 1920 and an attack of bronchitis in 1935 . He had been subject to winter cough and attacks of bronchitis almost all his life. Born and bred in Cambridge, he had worked as a joiner, was teetotal and smoked about four ounces of tobacco a week. His father and mother both died of "old age" at the ages of 65 and 70 respectively. Two sisters and one brother were alive and well and there was nothing significant in the family history.
He was rather thin (weight 8 st. $3 \mathrm{lb}$.) and looked his age. His temperature was $99^{\circ} \mathrm{F}$. and his pulse rate 100 . He complained of severe gnawing pain in both temporal regions and to a lesser extent in the shoulders, left arm, back, and legs.

The temporal arteries on both sides appeared swollen, tender, and tortuous, with small nodules along their course. Palpation gave a sensation of periarterial thickening and in places there was actual reddening of the skin over the line of the artery. The occipital arteries on both sides were similarly affected. He said that the swelling of his arteries had developed since his illness began. The rest of the cardiovascular system did not show any gross abnormality. There was slight tortuosity of the radial and brachial and slight narrowing of the retinal arteries. The blood pressure was $130 / 90$. Radiologically the heart was not enlarged. No evidence of disease was found in the other systems. Movements of the spine were free. The urine was normal. X-ray of the cervical region showed some osteoarthritis of the spine. X-ray of the skull did not show any abnormality. The blood urea was normal, the Wassermann reaction negative and the blood count normal but for a leucocytosis of 13,800 .

Progress.-After admission he ran in intermittent temperature of 100-101 occasionally rising to 102 for four weeks which then gradually settled. At the same time the pains in the head, the eye symptoms, and the redness of the skin and swelling around the arteries gradually subsided and his other pains also cleared up. On discharge his general condition also was very much better. In February 1939 he was seen again and all his symptoms and signs had disappeared except for slight tachycardia. He remained in fair health unil the following December when he developed a severe attack of bronchitis from which he died in January 1940.

Case 3.-An unmarried woman, aged 72, was under my care in Addenbrooke's Hospital in 1931 and was reported by Jennings (1938). She showed identical asymmetrical signs and symptoms in the temporal arteries, which lasted for about four months and then cleared up. While she was in hospital for five days her temperature varied between 99-100. She had a moderate degree of arteriosclerosis but no other evidence of disease. After she had recovered, she was able to live a quiet life at home appropriate to her age for two years until she collapsed suddenly one afternoon and died in a few hours.

No autopsies could be obtained.

\section{COMMENT}

These three patients all presented a strikingly 
similar clinical picture which agrees in all essential points with other descriptions of the disease. The age of onset was between 65 and 72, and the symptoms and signs produced by involvement of the temporal arteries were almòst identical and ran a similar course lasting from four to 'six months. All three showed evidence of arteriosclerosis in the radial and brachial arteries and two died suddenly from cardiovascular accidents. In addition to the severe symptoms arising from the temporal arteries in all three and from the occipital arteries in one, the following symptoms were also noted. Pain in the back and limbs in 2, fever in 2, weakness of the arm in 1 , blurring of vision in 1 and marked loss of weight in 1 . The association with angina of effort may have been a coincidence but Cooke found changes in the aorta and coronary arteries similar to those in the temporals.

In the majority of cases the key to the diagnosis has been severe headache leading to the discovery of involvement of the temporal arteries. If the characteristic picture is known, the diagnosis can be made on clinical grounds alone in the more obvious examples. In those that are more obscure it is important to remember the less obtrusive symptoms and signs so that they will be recognized even when the arteries of the scalp are not signally involved.

More cases should be published in order that the condition may be widely recognized and more may be learned about its protean manifestations. Robertson (1947) has recently described four more which he has observed in a single year. The fact that so many have been described since it was first noted and that some observers in different countries have each been able to collect several, suggests that it may be a good deal less rare than is supposed. More, too, has to be learned about prognosis which is difficult to assess in patients of this age. At present the general verdict is that it is good as far as the local condition in the temporal arteries is concerned, for this tends to clear up in about a year whatever treatment is given. It is not yet so clear how far extension of the process to other more vital arteries may be responsible for deaths such as occurred in these three patients and a follow-up of more cases is needed, supported by full post-mortem examination.

\section{REFERENCES}

Cooke, W. T., Cloake, P. C. P., Govan, A. D. T., and Colbeck, J. C. (1946). Quart. J. Med., 15, 47.

Horton, B. T., Magath, T. B., and Brown, G. E. (1932). Proc. Mayo Clin., 7, 700.
Jennings, G. H. (1938). Lancet, 1, 424.

Robertson, K. (1947). Brit. med. J., 2, 168. 